\title{
QUALITY BY DESIGN APPROACH: REGULATORY NEED, CURRENT, AND FUTURE PERSPECTIVE
}

\section{AAYUSHI RAJORA*, GURMEET CHHABRA}

Department of Quality assurance, Indore Institute of Pharmacy, Indore, Madhya Pradesh, India. Email: aauyrajora123@gmail.com

\author{
Received: 23 April 2019, Revised and Accepted: 08 May 2021
}

\begin{abstract}
Quality by design (QbD) is utilized in the event of pharmaceutical processes to create certain predefined product quality. QbD ideas unit of measurement explained in International Conference on Harmonization (ICH) pointers Q8 (R1) (Pharmaceutical development), Q9 (Quality risk management [QRM]), and Q10 (Pharmaceutical quality system). ICH Q8 (R1) guideline defines QbD as "a systematic approach to develop that begins with predefined objectives and emphasizes product and methodology, understanding, and methodology management, supported sound science and QRM." QbD approach studied the implications of various input variables (e.g. methodology parameters, and materials) of the merchandise development methodology, on the final word product (active pharmaceutical ingredient or drug product). The late QbD approach integrates the principles of QRM, and methodology analytical technology (PAT). QbD combined with methodology analytical technology (PAT) tools modify methodology management and increase assurance that the merchandise quality attributes unit of measurement achieved consistently. An integrated and risk-based approach for review of the merchandise development methodology is also a future need of the QbD plan. Although implementing the QbD approach is not a restrictive demand, restrictive agencies to supply flexibility in their pointers for producing that unit of measurement developed by the QbD approach. Rising trends embody the growing interest in quantifying and managing the impact of raw materials' attributes variability of methodology and product, what is more, as a result of the event of retrospective QbD approaches in complement to simple QbD. Thus, the QbD approach is also a tool for developing worth effective and quality pharmaceutical products.
\end{abstract}

Keywords: Quality by design, Risk management, International conference on harmonization guidelines, Retrospective quality by design.

(C) 2021 The Authors. Published by Innovare Academic Sciences Pvt Ltd. This is an open access article under the CC BY license (http://creativecommons.org/ licenses/by/4.0/) DOI: http://dx.doi.org/10.22159/ajpcr.2021v14i6.33733. Journal homepage: https://innovareacademics.in/journals/index.php/ajpcr

\section{INTRODUCTION}

The aim of the pharmaceutical company is based on manufacturing and innovation a quality product. The pharmaceutical company is constantly working to empower and ensure the safety, quality and efficacy of the product. However, drug recall, manufacturing failure, cost, scale-up issues, and burden in recent are some challenging factors for the industry. In traditional, the finished product evaluation unit ensures product quality and performance, with a limited understanding of the process and critical process parameters (CPP's). Regulatory bodies are therefore focused on implementation through quality by design (QbD) [1,2]. QbD is a science-based approach that reduces process variation and enabling process control strategies which result in improved process understanding and reliability. We do not have to rely on finishing product testing only, QbD provides transparency in the overall development process so that the quality issues can be analyzed efficiently and also, we can find and solve the basic problem quickly and efficiently. The requirement of QbD is determining the extent to which any changes can impact on the finished product quality. And, also the identification of all critical formulation attributes and related process parameters $[3,4]$

Definition (ICH [international conference on harmonization] Q8 [R1])

A systematic approach to development that begins with a predefined objective and emphasizes product and methodology, understanding and methodology management, supported sound science, and quality risk management (QRM) [5].

Definition (food and drug administration process analytical technology [FDA PAT] guidelines)

A system for designing, analyzing, and dominant manufacturing through timely measurements (i.e. throughout processing) of crucial quality and performance attributes of recent and in-process materials and processes to construct bounding final product safety.
QbD thought was printed as a result of the modern approach to the development of crucial methodology and quality product supported knowledge base throughout the event section of the merchandise [6].

\section{HISTORY AND BACKGROUND}

Quality intentionally (QbD) could be an idea introduced by the standard pioneer Dr. Joseph M. Juran believed that quality ought to be designed into a product, which most quality crises and issues related to the means within which a product was designed within the $1^{\text {st }}$ place. Limicoline bird undoubtedly a high-quality drug product as a product free from contamination and faithfully delivering the therapeutic profit secure on the label to the patron.

In 2002, a new initiative by a federal agency for risk management (cGMP for the $21^{\text {st }}$ century: a risk-based mostly approach). This began to modernize the regulation of FDA for pharmaceutical quality and to initiate a brand-new regulative framework supported QbD management of risk and quality system. This newer idea by FDA-cGMP initiative, two documents introduced by the ICH, for guiding the standard, that is, ICH-Q8: (pharmaceutical development) and ICH-Q9: (QRM).

In the gift century, the pharmaceutical business permits a lot of freedom to introduce new ideas, innovations, and enhancements which will enhance quality, cost, or timing [7-9].

\section{BENEFITS OF QbD}

QbD could be a sensible business that eliminates batch failures and minimize deviations and expensive investigation. $\mathrm{QbD}$ additionally avoids regulative compliance issues and structure learning could be reasonably invested within the future. Overall, $\mathrm{QbD}$ is sweet science that offers higher development selections and management of technical employees.

$\mathrm{QbD}$ is an economical, agile, and versatile system. It ensures consistent info and a much better risk management; a knowledge domain is made 
primarily for all merchandise. Thanks to these edges the producing potency is redoubled and producing value are reduced $[10,11]$.

\section{KEY ELEMENTS OF QBD}

These parts of a $\mathrm{QbD}$ approach to development that are [10]:

1. Shaping the Target Product Profile (TPP) because the correlation of quality, safety, and effectiveness is done.

Identification of the standard characteristics of the merchandise as a basis for the planning and development of the merchandise.

2. Determine critical quality attributes (CQA's)

Important Quality Attributes square measure the merchandise material properties that ought to be at intervals their acceptable limits, ranges, or distributed to make sure the specified product quality.

3. Comparison of material attributes and CPP's to the CQA's by Risk Assessment Risk assessment tools such as FMEA or bone diagram will determine the CPP's. ICH Q9 lists the tools which will be employed in the chance management system.

4. Institution of a space designing through the utilization of style of experiments (DOE's), a linkage and important interaction between the CQA's and CPP's may be established and represented in a very stylistic area.

5. Management strategy important sources of variability should be identified/understood and managed or controlled.

6. Management of product lifecycle and continual improvement (Fig. 1).

ICH Q10 describes a model for the institution of a good Quality Management System which will be utilized by makers implementing $\mathrm{QbD}$ systems and might value and improvise the quality of product throughout the merchandise lifecycle $[12,13]$.

TPP

TPP outlines the required profile or characteristics of a drug product that's geared toward a drug labeling and drug development activities. TPP state supposed use, target, the speed of administration, and alternative essential attributes of the product, as well as quality designing for a drug product [14]

\section{Target quality product profile (TQPP)}

TQPP may be a term that may be a natural extension of TPP for product quality. The QTPP is a vital document that allows the rationalization and

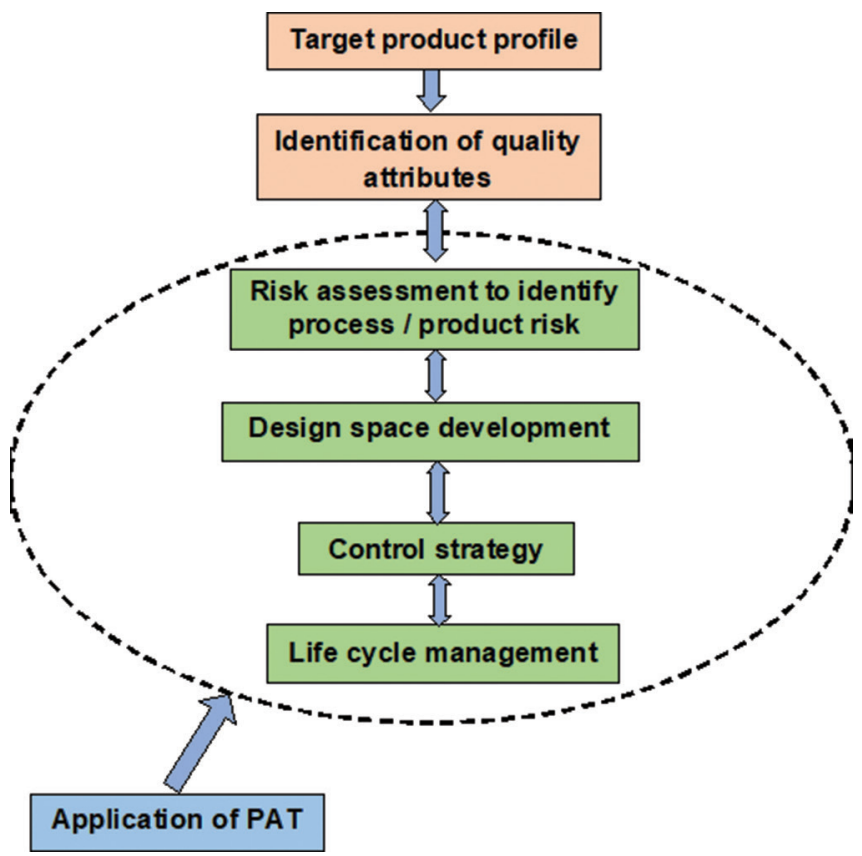

Fig. 1: Elements of quality by design [10] tracing the evolution of the data no inheritable throughout the lifecycle of the drug. "To confirm the targetive quality a prospective outline of the characteristics of quality for a drug product that are going to be achieved and taking into consideration the safety and effectiveness of the targetive product." TQPP embraces indefinite-quantity, type, indefinite-quantity, strength, instrumentation closure system, identity, as say, indefinite-quantity type, purity, and stability [15].

\section{CQA's}

CQA are physical, biological, microbiological, and chemical attributes to give assurance that the product obtained will attain the desired quality, safety, efficacy, and stability. And, that can also be defined, measured, and continually monitored to ensure final product outputs remain within acceptable quality limits. Quality attributes include clinical safety and efficacy, manufacturing an attribute, and parameter boundary approach edge of failure, the criticality may differ for the APT manufacturing process, and level of criticality increase in risk [16].

\section{Critical material attributes (CMAs)}

A parameter is important once a true modification therein parameter will cause the product to fail to fulfill the QTPP.Thus, whether or not a parameter is important or not depends on the however giant of an amendment one is willing to think about this as well as different properties or characteristics of associate input material. CMAs ought to be inside associate applicable limit, range, or distribution to make sure the required quality of that drug substance, excipient, or in-process material [17].

\section{CPP's}

CPP is outlined as any measurable input (input material attributes or operational parameter) or output (process state variable or output material attribute) of a method step that has got to be controlled to attain the required product quality and method uniformity. During this read, each item would be a method parameter. Parameters are monitored before or in processes that influence the looks, impurity, and yield of the ultimate product considerably [18].

\section{Risk assessment}

Risk is the combination of the chance of incidence of hurt and the severity of that hurt. Risk assessment helps to extend the quality of technique or process. A risk assessment will acknowledge crucial attributes that affect the ultimate quality of the product. A assessment of risk is useful for effective communication Between FDA And trades, research/development, and Producing and among multiple producing sites at intervals the corporate. Methods of risk assessment: Some strategies of risk assessment square measure mentioned in ICH guideline Q9 as follows [19]:

- Failure Mode Effects Analysis (FMEA);

- Failure Mode, Effects and Criticality Analysis (FMECA);

- Fault Tree Analysis (FTA)

- Hazard Analysis and critical control points (HACCP);

- Hazard Operability Analysis;

- Preliminary Hazard Analysis

- Risk ranking and filtering;

- Supporting applied mathematics tools.

\section{FMEA}

The most typically used risk-assessment tools within the pharmaceutical business is FMEA. To spot and mitigate the potential failure within the method, it is a scientific and proactive technique. Any errors or defects in an exceeding method, material, design, or instrumentality pictured in failure mode. Once failure modes, square measure established, the FMEA tool estimates the result of those failures and prioritizes them consequently. This tool is an additional advanced with the learning the results criticality and giving a clear indication of the state of affairs [20].

\section{FMECA}

It is that the addition of the earlier aforementioned FMEA tool. Extending independent agency to include an investigation of the 
degree of severity of consequences, their chances of prevalence and their detect-ability is a failure mode, effects, and criticality analysis. In FMECA, every failure mode of the merchandise is known and so evaluated for criticality. This criticality then translates into a risk, and if this level of risk isn't acceptable, corrective action should be taken. This could be used for failure and risk related to producing processes. The tool may also be want to establish and optimize maintenance plans for serviceable systems and/or contribute to regulating plans and different quality assurance procedures.

\section{FTA}

This tool assumes the failure of the practicality of a product or method. The results square measure pictured pictorially within the type of a tree of fault modes. Can be want to investigate complaints or deviation to perceive their root cause and make sure that supposed improvement will resolve downsides and not cause the other completely different problem.

\section{HACCP}

To control and monitor HACCP provides careful documentation to indicate method or product understanding through distinctive parameters. The definition of hazard includes each safety and quality concern in an exceedingly method or product. It involves hazard analysis, deciding important management purposes, establishing important limits, establishing a system to observe important management purposes, and establishing a record-keeping system. This can be wanted to establish and manage risk related to physical, chemical, and biological hazards [22].

\section{Design space}

It's multidimensional combination and interaction of input variables (e.g. material attributes) and method parameters that are incontestable to supply assurance of quality. Moving out of the planning area is taken into account to be an amendment and would usually initiate a restrictive post-approval amendment method (Fig. 2). The planning area is projected by the individual and is subject to restrictive assessment and approval. For the scientist, style, the area could be a Y (Quality Attributes) $=\mathrm{F}$ (Process Parameters Material Attributes) $-\mathrm{a}$ function or a relationship between (critical) method parameters and (critical) quality attributes/material attributes [23].

\section{Control strategy}

An effective strategy should be designed and managed to make sure the specified quality product that embraces raw material specifications, method controls, in-method testing, and final product testing. Critical method parameters and significant material attributes are known by this method. For this purpose, PAT is often effectively used which will later scale back depending on the style house to observe quality.

Elements of an Effective Strategy

- Procedural controls

- In-process controls

- Batch release testing



Fig. 2: Design space
- Method observation characterization testing

- Comparability testing

- Constancy testing.

The management strategy within the $\mathrm{QbD}$ commonplace is established through risk assessment that takes into consideration the criticality of the CQA's [21,22].

Product lifecycle management and continual improvement Product quality is often improved throughout the product lifecycle; firms have opportunities to choose creative approaches to boost quality. Method performance is often monitored to form certain consistency in quality. Extra expertise and information are gained throughout routine manufacture that contributes to method/process development. Periodic maintenance is often done at intervals a company's internal quality system; however, style area ought to be unchanged. The QbD approach avails the continual improvement throughout the products' lifecycle this can be a characteristic purpose of the traditional technique that is the way frozen method [23].

\section{Process analytical technique}

PAT has been printed by the U.S. FDA as a mechanism to vogue, analyze, and manage pharmaceutical manufacturing methods through the activity of vital process Parameters (CPP) that have a sway on vital quality attributes (CQA). The thought very aims at understanding the processes of shaping their CPPs, and consequently observance them throughout a timely manner (preferably in-line or on-line) and so being plenty of economical in testing whereas at the identical time reducing over-processing, enhancing consistency, and minimizing rejects. The authority has created public a restrictive framework for PAT implementation.

PAT could be a term used for describing a broader amendment in pharmaceutical production from static batch producing to a lot of dynamic approaches. It involves process the CPPs of the instrumentation accustomed, create the product, that have an effect on the CQA's of the product and so dominant these CPPs at intervals outlined limits. This enables makers to supply merchandise with consistent quality and additionally helps to scale back waste and overall prices [24].

This mechanism for manufacturing consistent product quality and reducing waste presents a decent case for utilizing continuous producing technologies. The management of a gentle state method once you perceive the upstream and downstream effects are a neater task as common cause variability is simpler to outline and monitor [25].

\section{PAT TOOLS}

To implement a productive PAT project, a mixture of 3 main PAT tools is essential:

Multivariate knowledge acquisition and knowledge analysis tools: typically, advanced software packages, packages that aid in the design of experiments, an assortment of raw information and statistically analyzing this data to see what parameters are CPP.

Process analytical chemistry tools: In-line and on-line analytical instruments accustomed live those parameters that are outlined as CPP. These embrace at the main close to infrared spectrometry (NIRS); however conjointly embrace biosensors, Raman spectrometry, and fiber optics [26].

\section{REGULATORY PERSPECTIVE}

Quality suggests that client satisfaction in terms of service, product, and method. Client demands the perfection in quality, reliability, low value, and timely performance. Client satisfaction is achieved by two ways in which, that is, options and free from deficiencies within the product. There are recent regulative developments that will cause a better want for the integrated use of QbD and quality. Regulative agencies, today, 
emphasize not just on "Quality by Testing" or "Quality by Chance" but solely on QbD.

\section{FDA PERSPECTIVE}

USFDA in 2005 asked to collaborate organizations to submit chemistry, manufacturing control info signifying the application of $\mathrm{QbD}$ as a part of the New Drug Application Table 1. QbD involves a scientific understanding of the method; a goal or objective is outlined before the actual process begins. For the implementation of $\mathrm{QbD}$, different parameters such as style house and real-time unharness risk assessment is to be performed. ICH in its Q8 pharmaceutical development, Q9 quality risk assessment, and Q10 pharmaceutical quality system offer strict necessities concerning product quality. Office conjointly states the importance of quality of the pharmaceutical product by giving method analytical technology (PAT) that may be a Structure for Innovative Pharmaceutical Development, producing, and Quality Assurance [26]

Based on the applying of product and method understanding, the FDA's office of new Drug Quality Assessment, was established a brand-new riskbased pharmaceutical quality assessment system. QbD helps to implement Q8 and Q9. FDA's read of QbD is "QbD may be a systematic approach to product and method style and development." This idea was accepted by

\section{Table 1: Regulatory bodies}

\begin{tabular}{ll}
\hline ICH (1999) & $\begin{array}{l}\text { Defines the thought of quality and assists within the } \\
\text { institution of worldwide specifications for brand new } \\
\text { drug substances or drug products. }\end{array}$ \\
FDA (2004a) & $\begin{array}{l}\text { Outlines the QbD thought and summarizes initiatives } \\
\text { to encourage science-based policies and innovation } \\
\text { in pharmaceutical development and production. } \\
\text { Proposes risk assessment as a tool to gauge the impact } \\
\text { of variations in method inputs on product quality. }\end{array}$ \\
FDA (2004b) $\begin{array}{l}\text { Introduces the PAT framework. Defines method } \\
\text { understanding, vital quality attributes, and important } \\
\text { method parameters, and identifies PAT tools. }\end{array}$ \\
$\begin{array}{l}\text { Introduces the important time unleash conception } \\
\text { Defines the manufacturing method because of } \\
\text { the set of activities associated with product style, } \\
\text { method style, and technology transfer. Acknowledges } \\
\text { that issues in these steps habitually derail or delay } \\
\text { development programs. }\end{array}$
\end{tabular}

FDA (2004c) Defines the conception of risk for pharmaceutical quality and provides principles and samples of tools for risk assessment and management.

ICH (2008) Describes a model for a good quality management system throughout the lifecycle of the merchandise. Outlines the management strategy and continuous improvement ideas.

ICH (2009) Provides an outline of QbD in pharmaceutical development. Defines most of the QbD Paradigms (quality TPP, important quality attributes, risk assessment, style, area, and management strategy), providing tips for his or her implementation and submission in technical documents.

ICH (2010) Proposes queries and answer sessions to facilitate the implementation of the Q8/Q9/ Q10 tips. Provides many clarifications and therefore the restrictive perspective in the main centered on QbD topics as style area, realtime unleash testing, and management strategy.

ICH (2011) Provides a guide for ICH Q8/Q9/Q10/Q11 guideline implementation, with stress on criticality identification, management strategy, style area, and method validation. Introduces the employment of modeling as a tool to implement $\mathrm{QbD}$ at each stage of development. Categories models and provides a top-level view for his or her implementation, validation and verification.

ICH: International conference on harmonization, FDA: Food and drug administration, PAT: Method of analytical technology, QbD: Quality by design the office in 2004 and careful description was given in pharmaceutical. cGMPs for the $21^{\text {st }}$ century - a risk-based mostly approach. In shell, product quality and performance are assured by coming up with economical producing processes. Risk-based regulative approaches are a unit for scientific understanding and management connected method for product quality and performance. Connected regulative policies and measure area unit changed to accommodate the important time knowledge base. Quality assurance may be a continuous method [27].

\section{ICH GUIDELINE AND QBD}

The principles of QbD, that is, Science- and risk-based development, risk assessment, lifecycle approach, and methodology style are explained within the quality pointers of the ICH. The relevant documents from the ICH of Technical necessities for Registration of prescription drugs for Human Use ICH-Pharmaceutical Development Q8 (R2); QRM Q9; Pharmaceutical Quality System Q10.

\section{REGULATORY CHALLENGES AND INSPECTION}

In a QbD idea, the restrictive burden is a smaller amount as a result of there are a unit wider range and limits supported product and method understanding. Changes among these ranges and limits don't need previous approval.

Conventionally, inspections are conducted victimization the FDA systembased approach and by CDER's Compliance Program "Inspection of accredited Biological Therapeutic Drug Products." However, within the present situation query arises that, however, the scrutiny can ensure wherever QbD is remitted. Throughout pre-license or preapproval inspections below a QbD idea, the FDA scrutiny team can assess the implementation and effectiveness of the method design as represented within the application and whether or not data and risk management are transferred with success from development to production. The scrutiny can evaluate the standard system and its effectiveness concerning consistent product quality, modification management procedures, method enhancements, deviation management, and data and risk management throughout the product lifecycle. Review of the ability and instrumentality qualification and maintenance also as raw material screening and provider management are the same because it was performed antecedently. But design, testing, and observing programs that demonstrate lustiness and consistency would be highlighted.

The majority of pharmaceutical corporations feel that there is a necessity for less difficult steering on the way to implement QbD. Firms needed clarification from the federal agency on $\mathrm{QbD}$ terminologies, acceptable strategies, criteria to pick and deselect CQA's, standards by that to gauge the adequacy of controls, and criteria for analytical technique substitution $[28,29]$. Ten key challenges are the foremost problematic for QbD adoption. These challenges are evaluated by their connection against completely different drug varieties similarly at different levels of adoption.

The first four challenges occur at intervals companies:

- Internal placement (Disconnect between cross-practical areas, e.g. $\mathrm{R}$ and $\mathrm{D}$ and producing or quality and regulation).

- Lack of belief in the business case, that is, there are loads of uncertainty over the temporal order of and investment necessities for QbD implementation.

- Lack of technology to execute (e.g. Issue managing information, restricted understanding of vital quality attribute [CQA] implications).

- Alignment with third parties (i.e. The way to implement QbD with increasing reliance on suppliers and contract manufacturers?)

The next six challenges are directly associated with the regulative authority:

- Inconsistency of treatment of $\mathrm{QbD}$ across the administrative body

- Lack of tangible steering for business

- Regulators not ready to handle QbD applications

- The approach to secure regulative advantages Sis presently being 
shared doesn't inspire confidence

- Misalignment of international regulative bodies

- Current interaction with corporations isn't causative to QbD.

It is accepted that the challenges and issues related to the implementation of QbD will solely be resolved if there is economical communication between the business and therefore the regulative bodies $[29,30]$.

\section{CURRENT STATUS}

The ICH's Pharmaceutical Development guidelines, ICH Q8, the objective is to systematically deliver a high-quality product by building correct controls, understanding of your producing method, and observance of the correct parameters and attributes. It is a scientific, risk-based, holistic, and proactive approach to pharmaceutical development and is a deliberate style effort from product conception through development with a full understanding of however product attributes and processes relate to product performance.

Quality is not essential to be tested into the finished product, in reality, the finished product might not be tested for all attributes. Beneath QbD principles, regulators can enable corporations to believe in-process and method analytical technology (PAT) information to assure the factorymade product meets the established pre-determined quality attributes. Regulators' expectations square measure that the knowledge and conclusions associated with the product, likewise because the management strategy that assures that the product quality attributes square measure maintained, ought to be shared with them. The FDA's Center for Drug analysis and analysis has expressed its expectation relating to $\mathrm{QbD}$ as " $\mathrm{QbD}$ could be a systematic approach to product and method style and development" [30].

QbD involves the subsequent key elements:

- Target the product profile

- Determine CQA's

- Link raw material attributes and method parameters to CQA's and perform a risk assessment

- Develop a design space

- Design and implement a control strategy

- Manage the product lifecycle, together with continual improvement.

Both business and also the agency square measure continued to target $\mathrm{QbD}$ because it relates to the acceptance criteria for period unleash. However, period unleash provides producing flexibility and exaggerated quality assurance and could be a lot of trendy approaches to producing and controls.

\section{CURRENT APPLICATIONS OF QBD}

QbD is applied on an oversized scale within the pharmaceutical trade. A number of the applications are as follows

1. Application of Pharmaceutical QbD for the Solubility improvement and Dissolution of sophistication II BCS Drug, exploitation chemical compound, surfactants, and Crystallization Inhibitors: Development of Controlled-release Tablets [31].

2. Application of QbD to Development of Analytical Separation Methods: The necessity for the application of QbD to be applied to Analytical separation strategies was determined since these strategies are used for internal control analysis of API and drug products. The strategies used for investigation were HPLC and capillary electrophoresis strategies [32]

3. A QbD Approach on Starch-Based Nanocapsules: A Promising Platform for Topical Drug Delivery: The analysis aimed to develop a novel Starch primarily based Nanoparticles Carrier System for topical delivery of lipotropic bioactive molecules. The technique used to be the emulsification-solvent evaporation method [33].

4. Near-Infrared and Raman spectroscopic analysis as method analytical technology Tools for the producing of Silicone-based Drug Reservoirs:
FDA's method analytical technology [PAT] is a component of the QbD construct, it focuses on "improving the pharmaceutical development, producing and quality assurance through innovation in product and method development, method analysis, and method control" [34].

5. In the determination of impurity: Weiyong Li describes a three-step technique development/optimization strategy for HPLC assay/impurity strategies for prescribed drugs, i.e. Multiple-column/mobile part screening, additional optimization of separation by exploitation multiple organic modifiers on the mobile part, and multiple-factor technique optimization exploitation Plackett-Burman experimental styles.

6. In the development of associate HPLC technique for drug products/ substances: Four common important parameters in HPLC - gradient time, temperature, $\mathrm{pH}$ of the aqueous effluent, and stationary part square measure evaluated in the standard of the looking framework by the means that of PC modeling code and a columnar data [35].

7. Pharmaceuticals: The delivery of drugs at the suitable purity, potency, and delivery rate, are anticipated from the pharmaceutical products. Whereas pharmaceutical laws have beyond question protected the men from any of the unwanted harms that occurred early within the $20^{\text {th }}$ century.

8. In-gel manufacturing: QbD Approach of a Pharmaceutical Gel producing method, by close to infrared watching of Composition and Physical Parameters gel by exploitation the near-infrared spectroscopy (NIRS) technique with multivariate geometric tools.

9. Within the production and characterization of protein: A scientific quality on purpose (QbD) strategy was accustomed to develop and characterize a being antibody production method.

10. In Nanomedicine: $\mathrm{QbD}$ on a rational development of a stable liquid formulation of Nanomedicine products [36].

11. Biopharmaceuticals: QbD has additionally been applied to biopharmaceuticals. It is a quick-growing trade parallel to pharmaceutical. High expectation of regulative bodies is that one among the explanations for the adoption of $\mathrm{QbD}$ by industries. Producing biopharmaceuticals involves a variety of complicated processes, Chromatography is additionally the foremost necessary unit operation in the downstream process of biomolecules, several of the days it's the first step for purification. Then it's useful to use $\mathrm{QbD}$ to biopharmaceutical products. Recently $\mathrm{QbD}$ has been with success applied in deciding design space for the HPLC technique for analysis of water-soluble vitamins [37].

Quality TPP, CQA's, and important and critical Parameters were outlined that square measure as mentioned within the table. Response surface methodology was wanted to value the results of the CPPs on the CQA's of the ultimate product. The most issue moving strength and Young's modulus were the proportion of alcohol. From the results, a design space can be created.

12. Establishing system exploitation QbD Principles: An integrated set of risk assessments and their connected components developed by Roche/Genentech were designed to supply an outline of product and method data for the assembly of a recombinant antibody. This chapter describes the weather and tools that want to establish acceptance criteria and an attribute testing strategy (ATS) for product variants and a method connected impurities. The appropriate ranges for the CQA's square measure set supported their potential impact on effectiveness and safety/immunogenicity. This approach concentrates on the management of patient impacts, instead of merely maintaining a uniform analytical profile [38,39]. The ATS tools were designed to spot quality attributes that needed method and/or testing managements or that might be captured in a very observance system to alter the lifecycle management of the control strategy.

QbD was applied to Drug substance development (ICH Q11); Drug Product (ICH Q8 R2), Analytical methodology development. The office powerfully recommends incorporating QbD components in ANDA submissions since Jan 2013. It will be enforced in Biopharmaceuticals products too.

US office has already revealed 2 QbD implementation case studies1. Quality by choice for ANDAs: An Example for Immediate-Release 
Tablets April 2012. 2. Quality by choice for ANDAs: An Example for change unleash Tablets Gregorian calendar month 2011.

\section{FUTURE PERSPECTIVE}

In the future, the $\mathrm{QbD}$ is going to be accustomed to a far bigger extent. Conjointly it will be additionally applied within the production space, as a result of presently, its often used within the development space, wherever we tend to use the event approaches within the method. Quite often it's seen that after we attend the assembly stage it stalls, either as a result of we have to travel into a plant that is presently existed for production purpose or as a result of they will be resistant towards new developments, particularly inside the PAT part. If we can keep the present production inside the instrumentation limits that we have then its fine. However, after we have gotten toward the additional advanced and impactful a part of the standard intentionally approaches to PAT following controlled methods, this is often truly wherever we tend to square measure introduced to quite important resistance.

Some regulative Agencies conjointly initiate the $\mathrm{QbD}$ idea implementation like European Medicines Agency (EMA). The EU has conjointly discharged a document for "Real-Time Release." The applications that embody quality intentionally square measure welcome by the EMA. The (EMA) is showing partial interest in the applications that primarily support the idea of quality intentionally (QbD). Quality intentionally is truly an abstract approach that aims to make sure the standard of medicines using applied mathematics, analytical, and riskmanagement methodology severally within the style, development, and production of medicines. U.S. authority/EMA refers to ICH guidelines Q8, Q9, Q10, Q11, and Q12 for QbD implementation [40,41]. Currently, ICH is functioning on "Q13- Continuous Manufacturing" and "Q14- Analytical technique Development." These new ICH tips square measures are expected close to the future [40].

\section{CONCLUSION}

QbD methodology helps in characteristic and justifying TPPs, product and method understanding and helps in continuous improvement. Implementing $\mathrm{QbD}$ conception in development provides quality medicines to patients, production enhancements to makers with considerably reduced batch failures, and drug regulative bodies can have larger confidence within the strong quality of the product. QbD has gained importance within the space of pharmaceutical processes such as drug development, formulations, analytical technique, and biopharmaceuticals. The most reason behind the adoption of $\mathrm{QbD}$ is that the regulative necessities. Per se QbD is turned into a promising scientific tool in quality assurance within the pharmaceutical trade. The pharmaceutical industry needs regulative compliance, therefore on getting their product approved for promoting.

\section{AUTHOR CONTRIBUTIONS}

AR and GSC designed and conceptualized the study. AR wrote the manuscript and GSC checked and finalized the manuscript.

\section{CONFLICT OF INTEREST}

The authors declare that there is not any conflict of interests.

\section{AUTHORS FUNDING}

No funding is required for the manuscript.

\section{REFERENCES}

1. Woodcock J. The concept of pharmaceutical quality. Am Pharm Rev 2004;16:10-5.

2. Q9: Quality Risk Management. ICH Harmonized Tripartite Guidelines. International Conference on Harmonization of Technical Requirements for Registration of Pharmaceuticals for Human Use; 2006.

3. Q10: Pharmaceutical Quality System, ICH Tripartite Guidelines. International Conference on Harmonization of Technical Requirements for Registration of Pharmaceuticals for Human Use; 2007.

4. Lionberger RA, Lee LS, Lee L, Raw A, Yu L $\times$. Quality by design: Concepts for ANDAs. AAPS J 2008;10:268-76.

5. Q8 (R1): Pharmaceutical Development, Revision1, ICH Harmonized Tripartite Guidelines, International Conference on Harmonization of Technical Requirements for Registration of Pharmaceuticals for Human Use; 2007.

6. FDA Guidance for Industry and Review Staff: Target Product Profile a Strategic Development Process Tool (Draft Guidance);

7. Patricia VA; 2007. Available from: http://www.pharmtech.com/ pharmtech/article/articleDetail.jsp?id=469915.

8. Aloka S, Robert I. Question base review (QbR) forms the platform of QbD principle. Technical 2009;15:8-10.

9. Nick T. Available from: http:/www.inpharmatechnologist.com/ Processing/FDA-publishes-QbD-example-to-help-genericsfirms-fileANDAs.

10. Callis JB, Illman DL, Kowalski BR. Process analytical chemistry. Anal Chem 1987;59:624A-37.

11. Yu LX. Pharmaceutical quality by design: Product and process development, understanding, and control. Pharm Res 2008;25:781-91.

12. Peterson JJ, Snee RD, McAllister PR, Schofield TL, Carella AJ. Statistics in pharmaceutical development and manufacturing. J Qual Technol 2009;411:111-34.

13. Nasr MM. Quality by Design (QbD) a Modern System Approach to Pharmaceutical Development and Manufacturing FDA Perspective; 2007.

14. Food and Drug Administration. Available from: http://www.fda.gov/ ohrms/dockets/ac/06/minutes/2006-4228m1.pdf.

15. US Food and Drug Administration; Guidance for Industry: Q10 Pharmaceutical Quality Systems; 2009.

16. Nasr M. Risk-based CMC Review Paradigm, Advisory Committee for Pharmaceutical Science Meeting; 2004.

17. Food and Drug Administration CDER. Guidance for Industry: Immediate Release Solid Oral Dosage Forms Scale-up and Postapproval changes: Chemistry, Manufacturing, and Controls, in vitro Dissolution Testing, and in vivo Bioequivalence Documentation; 1995.

18. Food and Drug Administration CDER. Guidance for Industry: Modified Release Solid Oral Dosage Forms Scale-up and Post-Approval Changes: Chemistry, Manufacturing, and Controls, in vitro Dissolution Testing, and in vivo bioequivalence documentation; 1997.

19. Rozet E, Marini RD, Ziemons E, Boulanger B, Hubert P. Advances in validation, risk and uncertainty assessment of bioanalytical methods. J Pharm Biomed Anal 2010;55:848-58.

20. World Health Organization. WHO Guideline on Quality Risk Management a Draft Guidance August. Geneva: World Health Organization; 2010.

21. Gibson M. Product Optimization: Pharmaceutical Preformulation and Formulation. New York: Taylor and Francis; 2001.

22. Seely RJ, Haury J, Rathore AS, Sofer G, editors. Process Validation in Manufacturing of Biopharmaceuticals. Boca Raton, FL: Taylor and Francis; 2005. p. 13-50.

23. US Food and Drug Administration. Guidance for Industry: Q10 Quality Systems Approach to Pharmaceutical. Vol. 3. Silver Spring: US Food and Drug Administration;

24. Food and Drug Administration. Guidance for Industry: PAT a Framework for Innovative Pharmaceutical Development, Manufacturing and Quality Assurance. Silver Spring: Food and Drug Administration; 2004.

25. Hinz DC. Process analytical technologies in the pharmaceutical industry: The FDA's PAT initiative. Anal Bioanal Chem 2006;384:1036-42.

26. Food and Drug Administration. Pharmaceutical cGMPs for the $21^{\text {st }}$ Century a Risk-based Approach; Final Report, September. Silver Spring: Food and Drug Administration; 2004.

27. Miksinski SP. Regulatory Assessment of Applications Containing QbD Elements: FDA Perspective. Meeting of the Advisory Committee for Pharmaceutical Science and Clinical Pharmacology, 27 July; 2011.

28. Jain S. Quality by design (QbD): A comprehensive understanding of implementation and challenges in pharmaceuticaldevelopment. Int J Pharm Pharm Sci 2013;6:29-35.

29. Drakulich, A. Critical challenges to implementing QbD: A Q and A with FDA. Pharm Technol 2009;33:90-4.

30. Moheb MN. Implementation of Quality by Design (QbD) Current Perspectives on Opportunities and Challenges Topic Introduction and ICH Update, Office of New Drug Quality Assessment OPS/CDER/ FDA Advisory Committee for Pharmaceutical Science and Clinical Pharmacology; 2014

31. Basalious EB, El-Sebaie W, El-Gazayerly O. Application of pharmaceutical QbD for enhancement of the solubility and dissolution 
of Class II BCS drug-using polymeric surfactants and crystallization inhibitors: Development of controlled-release tablets. AAPS Pharm Sci Tech 2011;12:799-810

32. Orlandini S, Pinzauti S, Furlanetto S. Application of QbD to development of analytical separation methods. Anal Bioanal Chem J 2013;405:2-3.

33. Marto J, Gouveia LF, Gonclaves LM. A QbD approach on starch-based nanocapsules: A promising platform for topical drug delivery. Colloids and Surfaces B Biointerfaces 2016;143:177-85.

34. Montanus J, Rozet E. Near-infrared and Raman spectroscopy as process analytical technology tools for the manufacturing of silicone-based drug reservoirs. Anal Chim Acta 2011;699:96-106.

35. Cyrus DA, Patrick JF, Muhammad JH, Sau L, Mansoor AK, Rakhi BS. Application of quality by design elements for the development and optimization of an analytical method for protamine sulfate. J Pharm Biomed Anal 2012;25:61.
36. Visser JC, Dohmen WM, Hinrichs WL, Breitkreutz J, Frijlink HW, Woerdenbag HJ. Quality by design approach for optimizing the formulation and physical properties of extemporaneously prepared orodispersible films. Int J Pharm 2015;485:70-6.

37. Schweitzer M, Pohl M, Hanna-Brown M, Nethercote P, Borman PJ, Hansen G, et al. Implications and opportunities of applying qbd principles to analytical measurements. Pharm Technol 2010;34:52-9.

38. Rathore AS. Roadmap for implementation of quality by design (QbD) for biotechnology products. Trends Biotechnol 2009;27:546-53.

39. Yu LX. Pharmaceutical quality by design: Product and process development, understanding, and control. Pharm Res 2008;25:781-91.

40. Kadam VR, Patil MP, Pawar VV, Kshirsagar S. A review on: Quality by design (QbD). Asian J Res Pharm Sci 2017;7:197-204.

41. Aksu B, Yeğen G. Global regulatory perspectives on quality by design in pharma manufacturing. Pharm Qual Des 2019;2019:19-41. 